\title{
Notas sobre redes, Estado e políticas públicas
}

Notes on networks, the State, and public policies

Notas sobre redes, Estado y políticas públicas

\section{Resumo}

Esse artigo apresenta sucintamente e problematiza a utilização da análise de redes sociais como método para a investigação de politicas públicas. Amplamente disseminada a partir dos anos 1970, a análise de redes permite o estudo das politicas com a consideração simultânea dos vários atores que influenciam a produção de politicas. A matriz pluralista da literatura de policy networks, entretanto, a distancia das premissas da sociologia relacional e dificulta a utilização da perspectiva para casos como o brasileiro, marcado pela multiplicidade de atores estatais e societais conectados por diversos tipos de vínculo, com destaque para os informais. Essas particularidades podem ser solucionadas com a articulação de categorias desenvolvidas recentemente como tecido relacional do Estado e governança, desde que devidamente integradas à análise. O quadro conceitual resultante representa uma ferramenta poderosa para a compreensão da influência de padrões relacionais sobre a produção de politicas públicas.

Governança; Rede Social; Politica Pública

\author{
Correspondência \\ E. C. L. Marques \\ Universidade de São Paulo. \\ Av. Prof. Luciano Gualberto 315, sala 2047, São Paulo, SP \\ 05508-900, Brasil. \\ ecmarq@uol.com.br \\ 1 Universidade de São Paulo, São Paulo, Brasil.
}


Este artigo visa a discutir e problematizar o uso das redes sociais como método para análise das políticas públicas, tema de especial interesse para a área da saúde pública. A análise de redes sociais é uma metodologia consolidada de investigação sobre os padrões dinâmicos de conectividade entre múltiplas entidades por diferentes tipos de relações, formais e informais, materiais e imateriais, ou mesmo redes pensadas e imaginadas.

O uso das redes no estudo de políticas tem crescido substancialmente no Brasil nos últimos anos. Uma rápida pesquisa realizada em abril de 2018 no portal de periódicos SciELO com a expressão "redes sociais" indicou 1.366 artigos, sendo apenas 110 deles publicados anteriormente a 2005 e 1.256 artigos desde então. Outra busca com "redes sociais" e "políticas públicas" (tanto no singular quanto no plural) indicou 135 artigos, nada menos do que 122 deles publicados depois de 2005.

Em geral, a utilização desse método visou a solucionar uma das críticas aos modelos convencionais sobre políticas públicas focados em atores singulares e autárquicos na decisão e na implementação. Constitui-se, então, um campo de estudos que operacionalizou analiticamente a ideia de que as políticas públicas são influenciadas por ações localizadas simultaneamente em inúmeros lugares e envolvem conjuntos por vezes amplos de atores, tanto na formulação quanto na implementação. A combinação do uso das redes com os conceitos de tecido relacional do Estado e de governança permite adicionar a essas estruturas relacionais as dinâmicas políticas que nelas ocorrem.

É claro que políticas públicas distintas têm graus diversos de centralização de seus processos de produção, envolvendo por vezes conjuntos mais amplos ou restritos de atores relevantes. Em políticas produzidas com intensa interdependência entre organizações estatais e não estatais, além de burocracias diversas e usuários, em múltiplas escalas simultâneas, como é o caso da saúde pública, a análise de redes pode ter contribuição bastante importante. Nesses casos, as redes permitem expandir as fronteiras dos estudos sobre políticas, incorporando de forma não apriorística atores e processos localizados no ambiente que cerca o Estado, tanto os altos escalões das elites políticas e da alta burocracia, quanto no chamado "nível da rua", com burocracias de nível da rua, organizações da sociedade civil e usuários de serviços.

Antes de iniciarmos, entretanto, é preciso estabelecer uma distinção importante, dada a circulação da expressão "rede" na área da saúde. Na organização de vários serviços públicos, a expressão "rede de serviços" ou "rede de equipamentos" é usada de forma corrente. Nesse caso, faz-se menção à existência concreta de conjuntos de entidades conectadas por relações pré-estabelecidas de natureza formal ou mesmo hierárquica, constituindo um sistema. Pois bem, o sentido de rede utilizado neste artigo se distancia muito dessa acepção, embora a análise de redes também possa ser usada para explorar essas redes. Entretanto, como discutirei mais adiante, a maior potência das redes está na sua utilização para desvendar as diversas e mutantes superposições entre padrões formais e informais na constituição das situações sociais. $\mathrm{O}$ artigo não detalha ou discute elementos técnicos envolvidos na análise, sendo o leitor referenciado para a literatura especializada para isto 1.

$\mathrm{O}$ artigo está dividido em três seções, além desta introdução e da conclusão. Na seção que segue, reconstituo brevemente a origem da aplicação das redes ao estudo das políticas, assim como apresento os principais elementos levantados pela principal literatura de redes desenvolvida nos anos 1980 e 1990 para o estudo das políticas, a das chamadas policy networks. Na segunda seção, discuto a forma pela qual versões mais sociológicas da análise de redes incorporam uma certa ontologia social, a meu ver mais apropriada para o uso do método no contexto brasileiro, ao menos. A terceira seção parte de tal ontologia para problematizar as policy networks, em especial com base em estudos brasileiros, de forma a aproximar os conceitos de nossa realidade. Ao final, sumarizo os principais elementos do artigo.

\section{O lugar da interação nos processos de produção de políticas}

Os principais modelos de análise de políticas públicas desenvolvidos pela ciência política a partir dos anos 1940 e 1950 partiam de três premissas: as políticas seriam definidas (i) no momento da decisão,

(ii) de forma racional e (iii) por atores singulares, autárquicos e isolados.

A centralidade da decisão e o seu caráter racional foram objetos de diversas críticas desde os anos 1950, contribuindo para a construção de interpretações muito mais sofisticadas sobre as políticas 
públicas 2 . A crítica ao caráter autárquico da decisão demoraria mais tempo. É verdade que no final dos anos 1950 Charles Lindblom já havia levantado a ideia de que a produção de políticas ocorreria por meio de processos de adaptação sucessiva (e iterativa) entre decisores. E é também verdade que a influência de conexões entre atores sobre as políticas governamentais não era estranha à ciência política, sendo a ação dos grupos de interesse central para o próprio pluralismo. Autores dessa tradição pluralista mostraram mesmo que, ao menos em alguns casos, se conformariam padrões relativamente estáveis de relações entre atores, dando origem aos "triângulos de ferro" ou "subgovernos", associando parlamentares, burocratas e eleitores 3 .

Entretanto, essas interpretações continuavam considerando a decisão centrada nos poucos atores formalmente encarregados delas e não é exagero sustentar que apenas no final dos 1970 o caráter autárquico da formulação de políticas seria colocado em xeque com o conceito de "redes de políticas públicas”. O primeiro autor a chamar atenção especificamente para a questão foi Hugh Heclo 4 , que discordava que a produção de políticas ocorresse centrada em atores singulares que tomassem decisões de forma autárquica e isolada. Em sentido mais específico, criticava também a ideia de que o padrão de intermediação de interesses presente nas políticas ocorresse por meio de triângulos de ferro, defendendo que a produção de políticas ocorreria por intermédio de redes que incluiriam conjuntos mais amplos de atores envolvidos com cada política ou dela demandantes, estatais e não estatais. Esses seriam frouxamente conectados por vínculos instrumentais e não instrumentais, mas também pela comunhão de visões do setor de política e pela mobilização em torno de assuntos específicos, razão pela qual as denominou issue networks.

Uma ideia semelhante foi desenvolvida para Hjern \& Porter 5 analisarem a implementação de políticas, denominando-as de implementation structures. Para os autores, o caráter de influência mútua entre atores também se faria presente na implementação, constituindo "estruturas de implementação" que conectariam burocracias governamentais e atores do mercado por meio de diversos tipos de relação. Como consequência, a unidade de análise das políticas não poderia corresponder às organizações ou agências isoladamente, mas ao conjunto delas em relação. Nessas estruturas de implementação, as políticas seriam pautadas pelas relações informais e conexões não oficiais, em constante dinâmica e mudança, recompondo os atores participantes. A entrada e a saída dos atores seria produto tanto de troca de benefícios mútuos entre participantes quanto de coerção ou indução de certos atores. Cada estrutura de implementação teria suas formas próprias de coordenação interna e com as demais, assim como graus de coesão específicos.

Seguindo os passos de Heclo \& Hjern, a ciência política começou a explorar a utilização de redes em três linhas de análise: estudos sobre elites, poder e corporações; investigações sobre movimentos sociais e mobilizações coletivas; e estudos sobre políticas públicas ${ }^{6}$. Considerando-se os objetivos deste artigo, me concentro o último grupo, embora haja conexões com as demais linhas.

A partir dos anos 1980 se constituiu uma agenda de pesquisas sobre políticas do Estado como produto da interação entre entidades públicas, privadas e grupos em policy networks. Essas redes seriam estruturadas em ambientes marcados pelas características institucionais, pelos padrões de relação pré-existentes e suas posições relativas, e pelos recursos de poder à disposição dos diversos atores 7,8,9. Embora partindo de premissas teóricas pluralistas, os autores tentaram construir uma "abordagem melhor informada sociologicamente sobre o comportamento dos grupos de interesse" 7 (p. 7). Essa análise permitiria mapear e compreender os padrões de relação que estruturariam os diversos setores de políticas em vários países, influenciando a forma como os atores e grupos se comportariam e agiriam estrategicamente. No que diz respeito às relações entre Estado e interesses privados, além de destacar as relações entre atores privados e públicos teorizados como triângulos de ferro, as análises das policy networks propuseram a existência de estruturas mais permanentes e menos orientadas a fins, conformando o que Heinz et al. 10 (p. 8) chamaram de "atributos estruturais da influência".

A unidade básica da análise seria os chamados policy domains - subsistemas ou campos de política pública delimitados pelas organizações formais identificadas por reconhecimento mútuo de relevância e orientação comum no que diz respeito a formular, defender e selecionar ações no domínio, excluindo as organizações que não são levadas em conta pelos participantes principais 11. Os atores pertenceriam ao Estado e à sociedade e estariam envolvidos nas políticas por contatos organizacionais de diversas formas 7,9, lobby e busca de influência 10, arenas de representação como conselhos de políticas 12 , ou a aquisição de ativos 13 em políticas como trabalho, energia, saúde, recursos hídricos e 
privatização. $\mathrm{O}$ estudo das redes permitiria reproduzir a estrutura do domínio em termos de proximidades e posições entre atores e tipos de atores, mapeando alianças, mediações, oposições e constrangimentos para a ação política. No interior de tais estruturas, os atores teriam acesso a instrumentos de poder não analisáveis apenas com os instrumentos convencionais da análise de políticas, sendo a influência explicada pelas relações organizacionais mobilizadas de forma intencional no domínio, em oposição a vínculos individuais 9 . Entretanto, vale dizer que a grande maioria das análises focou em organizações formais, assim como em relações formais e intencionais - "assumimos que entidades organizacionais - como associações comerciais, sociedades profissionais, sindicatos, grupos de interesse público, agências governamentais e comitês do Congresso - são os atores chave dos domínios de política estatal", considerando que "pessoas são importantes apenas na medida em que agem em nome e em benefício de coletividades" 7 (p. 9). Essa concentração dos estudos em organizações e em vínculos formais, organizacionais e intencionais é certamente herança da visão de poder do pluralismo, entendido apenas como conflito aberto. Dadas essas premissas, dimensões de poder associadas a conflito oculto, à mobilização de viés e influência ficaram de fora das análises, limitando as análises, sobretudo, em contextos de baixa institucionalização como o brasileiro.

\section{A ontologia relacional, as redes e a governança em políticas}

Os problemas assinalados anteriormente são oriundos da ênfase pluralista da literatura de policy networks, mas estes não são causados pela análise de redes, mas derivam dos paradigmas de explicação de políticas dos quais partiram seus atores 2. É importante, portanto, situar o leitor com relação às premissas teóricas e às dimensões de método envolvidas na análise de redes sociais. A análise de redes é uma perspectiva teórica e metodológica que considera que os mais variados fenômenos sociais devem ser analisados considerando-se os padrões de relação entre as entidades sociais envolvidas com o fenômeno. A literatura internacional sobre análise de redes sociais é ampla e diversificada, com uma já longa história de utilização nas ciências humanas que é impossível de resumir neste espaço 14,15.

Em termos mais teóricos, entretanto, trata-se da incorporação de forma profunda de uma ontologia relacional do social - a premissa de que o mundo social é feito de relações de vários tipos entre inúmeras e variadas entidades sociais em constante transformação. Nesse sentido ontológico, a consideração das redes já estava presente em clássicos das ciências sociais, mas de forma mais explícita em Georg Simmel. Ao longo de sua trajetória, as ciências sociais desenvolveram três formas de incorporar as redes em suas análises. Em primeiro lugar, e de caráter mais geral, está a utilização do conceito de rede como metáfora, levando em conta a ontologia relacional do social, mas sem operacionar uma investigação empírica que as utilize como metodologia de pesquisa específica. Esse uso é certamente o mais antigo e disseminado, estando presente em inúmeros estudos que trabalham, às vezes de forma periférica, com a questão de que entidades, indivíduos ou mesmo ideias estão de alguma forma conectados entre si. Uma segunda utilização do conceito de redes tem função normativa, propositiva e concreta, sendo pensada como parte de um sistema específico existente ou a desenvolver (normalmente formal, mas não necessariamente), usualmente pensado de forma a ser otimizado. Esse é o sentido corrente das redes de equipamentos ou redes de serviços na área da saúde, assim como das discussões do terceiro setor sobre redes de ONGs. Nesse caso, objetiva-se normalmente otimizar as relações em redes de entidades e de serviços de forma a reduzir tempos e recursos ou aumentar produtividades, efetividades e resolutividades, interferindo nas localizações de atividades, insumos e equipamentos, ou nos procedimentos institucionais que formam, incentivam e mantêm tais relações. Embora muito importante para as discussões da área da saúde, não abordarei esse uso das redes neste artigo.

Por fim, e mais importante para nós neste artigo, a terceira forma de utilização do conceito de redes é a que diz respeito especificamente à análise de redes sociais. Trata-se de considerar as redes não apenas como metáfora da estruturação das entidades na sociedade, mas também como método para a descrição e a análise dos padrões de relação nela presentes. Essa utilização metodológica se baseia na chamada sociologia relacional 16. Essa abordagem não pretende ser totalmente nova, visto que a ontologia relacional do social já estava presente nos clássicos das ciências sociais. Entretanto, a utilização dos métodos e das técnicas recentes permite focar as relações sociais em um novo patamar analítico, empurrando para o fundo da cena indivíduos (e seus comportamentos), atributos de grupos 
e processos macroestruturais, elementos priorizados analiticamente por boa parte das ciências sociais do século XX. As primeiras análises dessa perspectiva criticaram implícita ou explicitamente a elaboração de estudos que tentavam explicar ou compreender os fenômenos da sociedade por meio da observação de dados de categorias sociais ou atributos, em vez das informações referentes a relações. Dados de atributo dizem respeito a características ou qualidades de indivíduos ou grupos, e dados relacionais envolvem contatos, vínculos e conexões que relacionam os agentes entre si, e não podem ser reduzidos às propriedades dos agentes individuais 16 . Essa literatura entendia as instituições, a estrutura social e as características de indivíduos, e grupos são cristalizações dos movimentos, trocas e "encontros" entre as entidades, nas múltiplas e intercambiantes redes de relações ligadas e superpostas. A matéria- prima das ciências sociais seria, portanto, o conjunto das relações, vínculos e trocas entre entidades e não suas características ${ }^{17}$. Em um período mais recente, essa oposição entre atributos e relações foi afastada, inclusive pela conclusão de que em diversas situações sociais operam várias formas de construção mútua de atributos e relações por intermédio de processos de homofilia ${ }^{18}$, mas também de barreiras institucionais construídas baseando-se em atributos 19 .

Para Tilly 17, a incorporação mútua de relações e atributos permitiria a construção de um "estruturalismo a posteriori", que difere fundamentalmente das posturas estruturalistas anteriores por não partir de postulações de larga escala sobre as estruturas sociais, nem tampouco tentar derivar delas de forma indutiva os fenômenos sociais (como no funcionalismo e em várias versões do marxismo). Essa linha de análise parte do estudo de uma série de situações concretas para investigar a interação entre as estruturas relacionais presentes e as ações, estratégias, constrangimentos, identidades e valores dos atores. Segundo a sociologia relacional, as redes constrangem as ações e as estratégias, mas estas também as constroem e reconstroem continuamente. Da mesma forma, redes e identidades constituem mutuamente um processo complexo que apenas começa a ser explorado de forma detalhada.

A força da análise de redes sociais está na possibilidade de se construir estudos muito precisos em termos de aspectos descritivos, sem impor uma estrutura a priori à realidade e aos atores, e permitindo reinseri-los nos contextos em que operam, criando um tipo muito particular de "individualismo relacional" 17 , escapando também da excessiva fragmentação produzida por versões contemporâneas de individualismo metodológico, sobretudo na economia e na ciência política. Ao fazê-lo, essas análises permitem a realização de investigações sofisticadas e diretas, de nível intermediário, dos padrões de relação entre indivíduos e grupos, de forma a chegar aos tão decantados microfundamentos sem a perda de visão da estrutura social. A potencialidade aberta por tal metodologia não substitui de forma alguma a utilização de atributos ou o estudo de instituições, decisões, entre outras dimensões, mas como toda nova ferramenta analítica, a perspectiva abre um amplo campo de aspectos da realidade social e viabiliza novos olhares sobre fenômenos pouco compreendidos.

Uma dessas áreas de estudo potencial é justamente o Estado e sua interação com a sociedade. A utilização dessa perspectiva permite a consideração detalhada e empiricamente embasada dos padrões de vínculos entre os atores envolvidos nos processos de produção de políticas, assim como a análise das interconexões entre atores do Estado e da sociedade, que podem ser analisadas pela primeira vez sem que se recorra a um padrão de relações a priori, permitindo analiticamente como estes dois campos se interpenetram de forma complexa e reproduzindo de maneira mais precisa a realidade social.

Acredito que a aplicação das premissas da sociologia relacional às políticas pública pode ajudar a resolver alguns dos problemas apontados no estudo das policy networks. Como vimos, sua inspiração pluralista levou os estudos a considerar apenas vínculos entre organizações, desprezando conexões entre indivíduos, assim como centrando o foco em relações construídas intencionalmente. As dimensões de inércia que marcam os campos de ação estatal também são escassamente consideradas, sugerindo menor resiliência e constrangimentos do que os que usualmente envolvidos nas políticas. Nesse sentido, a incorporação das redes foi apenas parcial e muito mais centrada em dimensões técnicas do que na absorção plena da sociologia relacional. Esses problemas de ênfase são evidenciados claramente quando a perspectiva é aplicada a casos como o brasileiro, marcados por baixa institucionalização e pela presença de relações pessoais e de outros tipos conectando atores variados, e não apenas internos ao Estado.

A incorporação da ontologia relacional permite a reconstituição analítica de forma empiricamente embasada das estruturas relacionais em que ocorre a produção das políticas públicas. Entretanto, essas ainda representam estruturas de médio alcance estáticas, caso não incorporemos conceitual- 
mente elementos que permitam operacionalizar pesquisa empírica sobre as estratégias, ações, conflitos e alianças dos atores políticos no seu interior. A disseminação recente de certas acepções do conceito de governança pode ajudar nessa tarefa, não apenas conectando redes de políticas públicas à governança 20, mas principalmente destacando quem governa o que, e quem governa o que o Estado não governa 21 .

O termo governança é marcado por grande (e perigosa) polissemia. No caso das políticas públicas, entretanto, designa as diversas transformações recentes ocorridas no Estado, que descentraram a produção de políticas de agências e autoridades públicas, inserindo diversos atores de outros níveis de governo, da sociedade local ou nacional - empresas privadas, mas também ONGs e organizações da sociedade civil -, assim como atores supranacionais - entidades multilateriais, ONGs internacionais e órgãos como a União Europeia 22. A literatura parte da constatação geral de que políticas são cada vez mais produzidas sob a influência de conjuntos mais amplos de atores e instituições em diversos novos formatos de provisão - convênios, parcerias, contratos, concessões, esferas participativas, contratos de gestão, entre outros, embora os autores discordem ativamente se estas transformações são positivas 23 e negativas 24 .

No caso brasileiro, as interpretações têm oscilado entre associar o termo a formatos institucionais e práticas de gestão que geram eficiência econômica com a redução do Estado a outras que geram participação e controle social pela disseminação de novos formatos participativos 2 . Ambas as visões apresentam problemas conceituais, pois resumem a governança aos formatos com certo tipo de resultado (positivo), produzidos pela redução relativa da presença do Estado na produção de políticas (com maior presença do setor privado ou de entidades associativas). Acredito que o conceito de governança pode ser muito útil se a definirmos como os padrões de conexão entre atores e instituições por diversos tipos de vínculo, formais e informais, legais e ilegais, na produção de políticas, em especial se estas redes associadas às políticas forem compreendidas como conformando o tecido relacional do Estado, como veremos a seguir.

\section{As policy networks olhadas com base no tecido relacional do Estado}

Portanto, o ponto de partida para a construção de um arcabouço analítico para o estudo detalhado dos processos políticos que ocorrem na produção de políticas públicas é a consideração dos padrões relacionais entre os atores presentes em uma certa política ou comunidade ou campo de produção de políticas. Entretanto, é preciso escapar da ênfase das policy networks em relações formais e organizacionais, assim como da baixa centralidade do Estado em si naquela literatura. Segundo essa perspectiva 25 do funcionamento concreto da política (e das políticas), os contatos institucionais são canalizados por contatos pessoais e institucionais que se apoiam em padrões de relações preexistentes, assim como ajudam a recriá-los. Essas estruturas de médio alcance veiculam informações, apoios, alianças e a formação de projetos, visões e percepções. Adicionalmente, esses padrões de relação induzem visões de mundo (e da política), influenciam a formação de preferências, constrangem escolhas, estratégias e alianças e alteram resultados políticos. A desconsideração dessa dimensão tende a produzir uma visão excessivamente automática do funcionamento do Estado, desenraizando os atores e separando as estratégias políticas dos contextos sociais que as produzem.

Assim, diferentemente da maior parte da tradição das policy networks, devemos olhar simultaneamente para vínculos pessoais e organizacionais (em especial em contextos como o latino-americano). Embora as redes sempre envolvam uma dualidade entre pessoas de grupos ou organizações, a significância das relações pessoais em contextos de baixa institucionalização dos procedimentos como no Brasil tornaria as análises artificiais e ingênuas se fossem centradas apenas em vínculos institucionais. Não se trata de deslocar a ontologia relacional, nem de desconsiderar as organizações e focar apenas as redes pessoais, mas de levar em conta a mútua constituição de vínculos pessoais e organizacionais. Nesse sentido, laços construídos por indivíduos são induzidos pelas organizações em que se inserem e veiculam dimensões supraindividuais, mas com o tempo se tornam muitas vezes vínculos organizacionais.

Além disso, é necessário deslocar a ênfase incorporando não só vínculos orientados afins, mas também laços não intencionais construídos entre indivíduos e organizações em outros momentos do 
tempo, ou intencionais, mas com outras intenções associadas a outras conjunturas completamente diversas. As redes de políticas são apenas versões setoriais das redes sociais mais amplas que estruturam a sociedade em termos relacionais, grande parte destas construídas em outros momentos com objetivos diversos (ou mesmo sem objetivo algum).

Essas redes conformam uma estrutura relacional relativamente estável que podemos denominar de "tecido relacional do Estado" 25. A conformação de tal tecido influencia os conflitos políticos ocorridos no interior do Estado, visto que os atores mobilizariam ferramentas de poder associadas às posições relativas que ocupam. Além disso, esse tecido medeia a permeabilidade do Estado a atores localizados na sociedade e no mercado, especificando os padrões de intermediação de interesses presentes em cada política, tanto para grupos de elite (empresas privadas, políticos etc) quanto para atores societais e organizações populares e associativas.

A ideia de tecido relacional foi desenvolvida em dois estudos sobre políticas públicas e redes, posteriormente comparados 25 . A primeira pesquisa analisou as políticas de infraestrutura de saneamento básico na Região Metropolitana do Rio de Janeiro por uma empresa pública de nível estadual - a Cedae (Companhia Estadual de Águas e Esgotos do Rio de Janeiro) - entre 1975 e 1996. A companhia foi criada em 1975 com a fusão dos estados do Rio de Janeiro e da Guanabara, processo que levou à fusão das agências e organizações então existentes (no caso da Cedae, foram três empresas fundidas para a sua criação). O segundo estudo analisou as políticas de infraestrutura viária - pavimentação, abertura de vias, guias e sarjetas, microdrenagem, pontes, viadutos e túneis - desenvolvidas pela Secretaria Municipal de Vias Públicas entre 1975 e 2000. Considerando-se as estruturas institucionais, as duas políticas foram desenvolvidas por órgãos muito distintos em relação ao seu insulado, padrões de carreira e disponibilidade de recursos financeiros. De forma similar, os dois casos diferiam muito politicamente, com o Rio de Janeiro marcado por polarização política e alternância de poder, enquanto que em São Paulo observou-se uma forte e estável hegemonia de um único grupo político durante a maior parte do período.

As pesquisas analisaram as redes das comunidades de produção das duas políticas, construídas com base em informações de entrevistas sobre diversos tipos de vínculos entre os indivíduos do setor (pessoais, profissionais, políticos e de negócios). Os resultados sugerem que o tecido relacional do Estado é composto por uma superposição de redes de relações temáticas que circunscrevem as comunidades ligadas a cada uma de suas ações. Essas redes incluem todos os atores envolvidos com uma dada política, como técnicos do Estado, ou burocracias em um sentido mais geral, demandantes da política, contratantes da política e políticos e gestores que ocupam cargos eletivos e de livre indicação. Esses atores são conectados por vínculos de diversos tipos em constante transformação, sendo grande parte deles herdados de outros momentos. Essas redes apresentam um caráter fortemente inercial, estruturando o Estado internamente de maneira dependente da trajetória, governo após governo. $\mathrm{O}$ tecido relacional do Estado, portanto, constrói permanências no que para o pluralismo seria transitório, estruturando influências, alianças e oposições políticas e dando acesso a instrumentos de poder específicos a certos atores de forma desigual.

Por outro lado, essa estrutura é influenciada também pelas escolhas políticas dos atores mais importantes, visto que vínculos são efetivamente construídos e quebrados ao longo da gestão das políticas, inclusive de forma intencional. Na verdade, a alteração do tecido pode ser parte de estratégia política durante certos governos, que frente a oposições às suas políticas por parcelas expressivas da rede, introduzem inúmeros técnicos externos à comunidade e os tentam conectar a ela, desde fora. Nesse contexto, as relações pessoais podem ser unidades básicas de processos de construção institucional, ao contrário do que se afirma usualmente. Por outro lado, os processos de fusão institucional observados também sugerem a importância da interpenetração paulatina das redes ao longo do tempo na constituição da nova organização 25 .

Em termos políticos, o tecido relacional do Estado tem como consequência que as disputas internas ao Estado são polarizadas por grupos amalgamados por interesses (como gostaria o pluralismo), mas também por projetos comuns e por relações. Esses grupos, dependendo da estrutura de poder vigente em um dado campo ou comunidade, se associam com os detentores do poder institucional de forma negociada, trocando poder posicional pelo poder oriundo da investidura dos cargos. Nesse sentido, na dinâmica das políticas no interior das redes, um tipo específico de recurso de poder emerge, associado às posições ocupadas pelos indivíduos no tecido do Estado. Como a gestão cotidiana 
da política depende da mobilização de parcelas da rede, para a construção do poder infraestrutural do Estado 26, os detentores de cargos institucionais (principalmente eletivos, mas também indicados) negociam alianças com indivíduos das comunidades de políticas, trocando poder posicional (oriundo da ocupação de posições na rede) por poder institucional (oriundo da investidura de cargos).

As redes também estruturam as relações entre os campos do público e do privado, explicando uma parte importante da permeabilidade do Estado que subjaz às políticas do urbano no Brasil. Isso porque indivíduos, agências, organizações e empresas de dentro e de fora do Estado se encontram vinculadas de formas diversas, tanto por vínculos de trabalho e de caráter intencional, quanto por conexões construídas ao longo das trajetórias de vida dos indivíduos nos processos de formação técnica e profissional, nas associações profissionais ou mesmo nas suas trajetórias pessoais. Suas práticas conformam padrões de governança relativamente estáveis, sendo a permeabilidade do Estado substancialmente mais inercial e disseminada do que o considerado por categorias usadas anteriormente para descrever o fenômeno, como privação do Estado e anéis burocráticos do poder. Nesse sentido, empresas privadas tanto operam no interior do tecido utilizando as posições que conquistaram de forma paulatina na rede da política, mobilizando seu próprio poder posicional, quanto trocam poder econômico por poder posicional quando não dispõem deste último, em especial quando são de fora do setor, gerando corrupção. Entretanto, mais uma vez aqui as escolhas políticas importam, e as estratégias dos ocupantes dos principais cargos institucionais influenciam a maneira pela qual a permeabilidade ocorre, mantidas as demais condições institucionais e políticas.

Adicionalmente, a comparação dos dois casos estudados sugere que as redes tendem a apresentar mais importância e a influenciar mais fortemente as políticas quando as organizações estatais envolvidas são mais insuladas. No caso do Rio de Janeiro, onde a política era implementada por uma empresa estatal com estrutura de carreira e receitas próprias, a relação entre os detentores do poder institucional e os grupos no interior da rede tendia a ser de maior negociação, com substanciais recursos de poder nas mãos dos atores internos à comunidade. No caso de São Paulo, as políticas eram implementadas por um órgão da administração direta, sem insulamento ou espírito de corpo e com um intenso padrão de migração para fora e para dentro. Como consequência, a relação do poder institucional com a rede era muito mais desequilibrada, e as alternativas, projetos substantivos e ideias de políticas tendiam a emanar mais fortemente de fora da comunidade. Assim, em organizações mais insuladas, os projetos tendem a dialogar mais com grupos da comunidade no interior da rede, e em órgãos mais abertos as políticas implantadas tendem a expressar mais fortemente projetos vindos de fora.

Um caminho analítico similar foi seguido por outras investigações nos últimos anos para pesquisar políticas públicas no Brasil. Retornei à ideia de tecido relacional do Estado em período recente para explorar outra de suas camadas constitutivas 27. Estudando a cidade de São Paulo entre 1985 e 2012, investiguei sistematicamente a migração de indivíduos entre administrações e agências locais, com base em dados primários dos ocupantes dos três mais altos postos das agências municipais. $\mathrm{O}$ trabalho demostrou a existência de um complexo tecido, responsável potencialmente pela coordenação entre agências, áreas de política e no tempo, entre governos, com destaque para as agências de articulação política e administrativa, mas também para a Secretaria de Planejamento Urbano, responsável pelas políticas de uso do solo. Evidenciou-se ainda uma conexão mais intensa entre governos com afinidade ideológica, o que seria de se prever, mas também entre governos considerados opostos em termos político-partidários.

De especial interesse para a área da saúde e também mobilizando a ideia do tecido relacional do Estado figura um estudo sobre a regulação da área de saúde suplementar no Brasil em período recente 28 . O estudo iniciou por aspectos institucionais e organizacionais da formação da Agência Nacional de Saúde Suplementar (ANS) e do mercado de saúde suplementar, para investigar sistematicamente o comportamento decisório dos conselheiros e a política da agência, retratando as redes de apoio político e de indicações de conselheiros ao longo das várias administrações. Os resultados demonstram a importância das redes na conformação do campo, a presença de atores políticos e empresas privadas com papel de destaque, mas também a relevância de dimensões organizacionais da agência e suas burocracias para explicar os padrões de decisão.

O conceito de tecido relacional também ajuda a jogar luz sobre elementos e processos relacionais da sociedade influenciados por ações estatais. Dentre esses merecem destaque a análise sobre as redes dos agentes comunitários de saúde do Programa Saúde da Família 29, tentando investigar de que for- 
ma estes mobilizam vínculos e repertórios discursivos para executar as atividades de mediação que caracterizam sua posição na cadeia de produção da política de saúde. Seus resultados sugerem que a institucionalização dos programas reduz a discricionaridade das práticas dos agentes, mas não reduz o repertório de estilos por meio dos quais interagem com a demanda do programa.

\section{Conclusão}

Sumarizando, podemos dizer que a análise de redes sociais pode contribuir bastante para o estudo de políticas públicas ao permitir o desenvolvimento de análises que incorporem conjuntos de atores mais amplos e variados do que os sugeridos pelos modelos tradicionais, assim como levar à incorporação de forma empiricamente embasada dos entornos que cercam os agentes estatais formalmente encarregados pelas políticas.

Essa contribuição será em especial efetiva se os estudos se afastarem das versões pluralistas das policy networks, demasiadamente focadas em organizações e relações formais, perdendo justamente a maior vantagem da análise de redes, ligada ao caráter indutivo de seu estruturalismo. A incorporação da ideia de governança, entendida como os conjuntos de atores estatais, não estatais e instituições ligados por conexões de diversos tipos, nos ajuda a ligar as estruturas constituídas pelas redes com as estratégias e práticas dos variados atores políticos presentes nas políticas públicas. O conceito de tecido relacional do Estado, por fim, permite incorporar esse conjunto de elementos de forma integrada. Ao circunscrever analiticamente a parcela das redes constitutivas das sociedades centrada nos Estados, suas organizações, entorno e atividades, o conceito permite incorporar dinamicamente os diversos atores e processos presentes na produção de políticas públicas.

\section{Informação adicional}

ORCID: Eduardo Cesar Leão Marques (0000-00015569-858X).

\section{Agradecimentos}

À Fundação de Amparo à Pesquisa do Estado de São Paulo (Fapesp) e ao Centro de Estudos da Metrópole pelo apoio.

\section{Referências}

1. Hanneman RA, Riddle M. Introduction to social network methods. Riverside: University of California; 2005.

2. Marques E. Government, political actors and governance in urban policies in Brazil and São Paulo: concepts for a future research agenda. Brazilian Political Science Review 2013; 7:835.

3. Fiorina M. Congress: keystone of the Washington Establishment. New Haven: Yale University Press; 1989.

4. Heclo H. Issue networks and the executive establishment. In: King A, editor. The new American political system. Washington DC: American Institute for Public Policy Research; 1978. p. 87-107.

5. Hjern B, Porter D. Implementation structures: a new unit of administrative analysis. Organization Studies 1981; 2:211-27.

6. Knoke D. Political networks: the structural perspective. Nova York: Cambridge University Press; 1990.

7. Laumann E, Knoke D. The organizational state: social choice in the national policy domains. Madison: University of Wisconsin Press; 1987. 
8. Laumann E, Tam T, Heing J, Nelson R, Solisburg R. The social organization of the Washington establishment during the first Reagan administration. In: Moore G, Whitt A, editors. Research in politics and society: the political consequences of social networks. v. 4. Madison: University of Wisconsin Press; 1992. p. 161-88.

9. Knoke D, Pappi F, Broadbent J, Tsujinaka Y. Comparing policy networks: labor politics in the U.S., Germany, and Japan. Cambridge: Cambridge University Press: 1996.

10. Heinz J, Laumman E, Nelson R, Salisbury, R. The hollow core: private interests in national policy making. Cambridge: Harvard University Press; 1997.

11. Knoke D. Networks of elite structure and decision making. In: Wassermanm S, Galaskiewicz $\mathrm{J}$, editors. Advances in social network analysis. New York: Cambridge University Press; 1992. p. 274-94.

12. Schneider M, Scholz J, Lubell M, Mindruta D, Edwardsen M. Building consensual institutions: networks and the National Estuary Program. Am J Pol Sci 2003; 47:143-58.

13. Jordana I, Sancho D. Reforma del Estado y telecomunicaciones en América Latina. Barcelona: Universidade Pompeu Fabra; 2003.

14. Freeman L. The development of social network analysis. Vancouver: Empirical Press; 2004.

15. Scott J. Social network analysis. Newbury Park: Sage Publications; 1991.

16. Emirbayer M. Manifesto for a relational sociology. Am J Sociol 1997; 103:281-317.

17. Tilly C. Prisioners of the State. Int Soc Sci J 1992; 44:329-42.

18. McPherson M, Smith-Lovin L, Cook J. Birds of a feather: homophily in social networks. Ann Rev Sociol 2001; 27:415-44.
19. Tilly C. La desigualdad persistente. Madrid: Manatial; 2000.

20. Rhodes R. Understanding governance: ten years on. Organization Studies 2007; 28:124364.

21. Le Galés P. Urban policies in Europe: what is governed? In: Bridge $\mathrm{G}$, Watson S, editors. The new blackwell companion to the city. Oxford: Blackwell; 2011. p. 747-58.

22. Stoker G. Governance as theory: five propositions. Int Soc Sci J 1998; 50:17-28.

23. Pierre J. The politics of urban governance. Londres: Palgrave McMillan; 2011.

24. Davies J. Against partnerships: toward a local challenge to global neoliberalism. In: Hambleton R, Gross J, editors. Governing cities in a global era: urban innovation, competition and democratic reform. New York: Palgrave; 2007.

25. Marques E. Public policies, power and social networks in Brazilian urban policies. Lat Am Res Rev 2012; 47:27-50.

26. Mann M. Sources of social power: a history of power from the beginning to $1760 \mathrm{AD}$. Cambridge: Cambridge University Press; 1986.

27. Marques E. A rede dos gestores locais em São Paulo. Dados Rev Ciênc Sociais 2017; 60:43772.

28. Baird M. Redes de influência, burocracia, política e negócios na Agência Nacional de Saúde Suplementar (ANS) [Tese de Doutorado]. São Paulo: Universidade de São Paulo; 2017.

29. Lotta G. Burocracia e implementação de políticas de saúde. Rio de Janeiro: Editora Fiocruz; 2015. 


\section{Abstract}

This article briefly presents and analyzes the use of social network analysis as a method for studying public policies. Widely disseminated since the 1970s, network analysis allows the study of policies with simultaneous consideration for the various stakeholders that influence policymaking. The pluralistic matrix of the policy networks literature and the difference with the premises of relational sociology hinder the use of the approach for cases like Brazil, marked by the multiplicity of state and civil society actors with various types of links, especially informal ones. These specificities can be solved by linking the categories developed recently as the relational fabric for the state and governance, as long as properly integrated into the analysis. The resulting conceptual framework is a powerful tool for understanding the influence of relational patterns on the production of public policies.

Governance; Social Network; Public Policy

\section{Resumen}

Este artículo presenta sucintamente y problematiza la utilización del análisis de redes sociales como método para la investigación de políticas públicas. Ampliamente difundido a partir de los años 1970, el análisis de redes permite el estudio de políticas con la consideración simultánea de los varios actores que influencian la producción de políticas. La matriz pluralista de la literatura sobre policy networks, no obstante, la aleja de las premisas de la sociología relacional y dificulta su utilización para casos como el brasileño, marcado por la multiplicidad de actores estatales y societarios interrelacionados por diversos tipos de vínculos, destacando los informales. Estas particularidades se pueden solucionar con la coordinación de categorías desarrolladas recientemente como el tejido relacional del estado y su gobernanza, siempre que estén debidamente integrados en el análisis. El marco conceptual resultante representa una poderosa herramienta para la comprensión de la influencia de patrones relacionales en la generación de políticas públicas.

Gobernanza; Rede Social; Política Pública
Recebido em 05/Jan/2018

Versão final reapresentada em 10/Abr/2018

Aprovado em 02/Mai/2018 